\title{
Low SWaP Semiconductor Laser Transmitter Modules For ASCENDS Mission Applications
}

\author{
Narasimha S. Prasad ${ }^{1,}$ Alex Rosiewicz ${ }^{2}$, Steve Coleman ${ }^{2}$ \\ ${ }^{1}$ NASA Langley Research Center, 5 N. Dryden St., MS 468, Hampton, VA 23681 \\ ${ }^{2}$ EM4, 7 Oak Park Drive, Bedford, MA 01730
}

\begin{abstract}
The National Research Council's (NRC) Decadal Survey (DS) of Earth Science and Applications from Space has identified the Active Sensing of $\mathrm{CO}_{2}$ Emissions over Nights, Days, and Seasons (ASCENDS) as an important atmospheric science mission. NASA Langley Research Center, working with its partners, is developing fiber laser architecture based intensity modulated $\mathrm{CW}$ laser absorption spectrometer for measuring XCO2 in the $1571 \mathrm{~nm}$ spectral band. In support of this measurement, remote sensing of $\mathrm{O}_{2}$ in the $1260 \mathrm{~nm}$ spectral band for surface pressure measurements is also being developed. In this paper, we will present recent progress made in the development of advanced transmitter modules for $\mathrm{CO}_{2}$ and $\mathrm{O}_{2}$ sensing. Advanced DFB seed laser modules incorporating low-noise variable laser bias current supply and low-noise variable temperature control circuit have been developed. The $1571 \mathrm{~nm}$ modules operate at $>80 \mathrm{~mW}$ and could be tuned continuously over the wavelength range of $1569-1574 \mathrm{~nm}$ at a rate of 2 $\mathrm{pm} / \mathrm{mV}$. Fine tuning was demonstrated by adjusting the laser drive at a rate of $0.7 \mathrm{pm} / \mathrm{mV}$. Heterodyne linewidth measurements have been performed showing linewidth $\sim 200 \mathrm{kHz}$ and frequency jitter $\sim 75 \mathrm{MHz}$. In the case of $1260 \mathrm{~nm}$ DFB laser modules, we have shown continuous tuning over a range of $1261.4-1262.6 \mathrm{~nm}$ by changing chip operating temperature and $1261.0-1262.0 \mathrm{~nm}$ by changing the laser diode drive level. In addition, we have created a new laser package configuration which has been shown to improve the TEC coefficient of performance by a factor of 5 and improved the overall efficiency of the laser module by a factor of 2 .
\end{abstract}

Keywords: ASCENDS, DFB laser diodes, CO2 sensing, O2 sensing

\section{INTRODUCTION}

The National Research Council (NRC) Decadal Survey of Earth Science and Applications from Space has identified has identified Active Sensing of CO2 Emissions over Nights, Days, and Seasons (ASCENDS) as an important mid-term (tier II) and mid-size mission [1,2]. Figure 1 illustrates the ASCENDS mission goals. The ASCENDS mission is anticipated to deliver laser based remote sensing measurements of $\mathrm{CO}_{2}$ mixing ratios $\left(\mathrm{XCO}_{2}\right)$ day and night, at all latitudes, and during all seasons. ASCENDS includes simultaneous measurements of (a) $\mathrm{CO}_{2}$ number density tropospheric column, (b) $\mathrm{O}_{2}$ number density column that allows surface pressure measurement to derive average $\mathrm{XCO}_{2}$ column, (c) Temperature profile to obtain improved $\mathrm{CO}_{2}$ accuracy, (d) Altimetry measurements to determine surface elevation, cloud top heights, (e) carbon monoxide $(\mathrm{CO})$ profile to identify combustion sources of $\mathrm{CO}_{2}$. ASCENDS is the logical extension of (orbiting Carbon Observatory (OCO) and Greenhouse gases Observing SATellite (GOSAT) missions.

NASA Langley Research Center, in partnership with ITT, is working on a novel CW Laser Absorption Spectrometer (LAS) technique for simultaneous measurement of the $\mathrm{CO}_{2}$ column number density and the $\mathrm{O}_{2}$ column number density. Due to architectural advantages combined with reasonable spectroscopic features, the $1571 \mathrm{~nm}$ wavelength band is selected for $\mathrm{CO}_{2}$ measurements. For $\mathrm{O}_{2}$ measurements to determine surface pressure, the $12 \mathrm{xx} \mathrm{nm}$ band has been selected. The $\mathrm{O}_{2}$ column number density is used to convert the column number density to $\mathrm{CO} 2$ mixing ratio $\left(\mathrm{XCO}_{2}\right)$. An altimeter based on a pulsed laser operating around $1591 \mathrm{~nm}$ is utilized for path length measurement. Plans are underway to incorporate (a) a six channel passive radiometer based temperature profiler for constraining the $\mathrm{XCO}_{2}$ measurement, and (b) a passive $\mathrm{CO}$ measuring scheme using a gas filter correlation radiometer to separate biogenetic fluxes from biomass burning fossil fuel combustion to cover the same the $\mathrm{XCO}_{2}$ path for interpreting sources and sinks of $\mathrm{CO}_{2}$. 
Furthermore, an imager is being used to provide cloud clearing for soundings. Currently, NASA LaRC is collecting data from Commercial-of-the-shelf (COTS) based airborne instruments to verify the $\mathrm{CO}_{2}$ measurement capability of the laser based LAS approach. In this context, NASA is looking into advances in instrumentation concepts for reducing size, weight, volume, and power consumption while enhancing the signal-to-noise ratio of return signals. Previously, a working prototype with preliminary results were presented [3]. Under the recently awarded ASCENDS CarbonHawk Experiment Simulator (ACES) Instrument Incubator Program (IIP), NASA LaRC will be developing an enclosure incorporating advanced instrument subsystems with lowest possible SWaP that is compatible with the GlobalHawk platform. GlobalHawk aircraft will allow $\mathrm{XCO}_{2}$ sensing from $\sim 60,000 \mathrm{ft}$. altitude. Flight Tests using UC-12 and DC-8 aircrafts will also be carried out to test ACES instrument designs. In this paper, further advancements in seed laser development for ASCENDS transmitter applications are presented in the following sections.

\section{SEED LASER DESIGN GOALS}

Overall design goals of seed laser development for ASCENDS applications for $1571 \mathrm{~nm}$ and $1260 \mathrm{~nm}$ operation are as follows [3-5]:

- Stable Laser Line Position (Jitter)

- Linear temperature control

- Less than or equal to $1 \mathrm{MHz}$

- Narrow Laser Linewidth

- Low-noise current source via novel architecture

- Less than $300 \mathrm{kHz}$

- Tunability of Laser Line Position and Output Power

- Coarse tuning via temperature and fine tuning via chirp

- Total tuning range of $+/-2 \mathrm{~nm}$ and wavelength resolution of $<0.12 \mathrm{pm}$

- Large adjustments to power also achievable with correspondingly large adjustments to frequency

- Lowest Possible SWaP

- Linear temperature control is inefficient so DFB itself was redesigned to be more thermally efficient and require less current

- Overall volume $<2$ " x2" x 0.5 " (2 cu. In)

- Immunity to Electromagnetic Interference

- Commercial Viability with Path to a Space Qualifiable Design

Stability of DFB Laser output frequency is of importance to reduce bias during the data retrieval process. Several factors affecting the stability of DFB laser output frequency. "Chirp" is the variation of laser output frequency with applied drive current. Typical lasers chirp at a rate of $400-800 \mathrm{MHz} / \mathrm{mA}(3-6 \mathrm{pm} / \mathrm{mA})$ near their operating point..1pm line stability requires $\sim 100 \mathrm{uA}$ RMS current variation. Hence, better than $100 \mathrm{uA}$ RMS variation desired. DFB laser output frequency also tunes via temperature. Typical lasers tune at a rate of $-12.5 \mathrm{GHz} / \mathrm{K}(100 \mathrm{pm} / \mathrm{K}) .1 \mathrm{pm}$ line stability requires $10 \mathrm{mK}$ pk-pk temperature variation of laser chip. A low-noise, frequency stable laser requires a low noise current source and high stability temperature controller. Note that $1550.00 \mathrm{~nm}$ (vacuum) is equivalent to $193.414 \mathrm{THz}$ and $\Delta \lambda$ of $1 \mathrm{pm}$ is equal to $\Delta \mathrm{f}$ of $125 \mathrm{MHz}$.

\section{BASELINE DESIGN CONFIGURATION}

TFigure 1 shows the previously developed baseline design module EM650 that is now being modified to incorporate the above listed design features. This DFB laser module consists of laser cavity and integrated control electronics. The EM650 is a novel DFB laser integrated with (a) low-noise laser current source, (b) temperature control circuit, and (c) a back facet monitor photodiode amplifier. All these three features are integrated into an OEM-style package. 


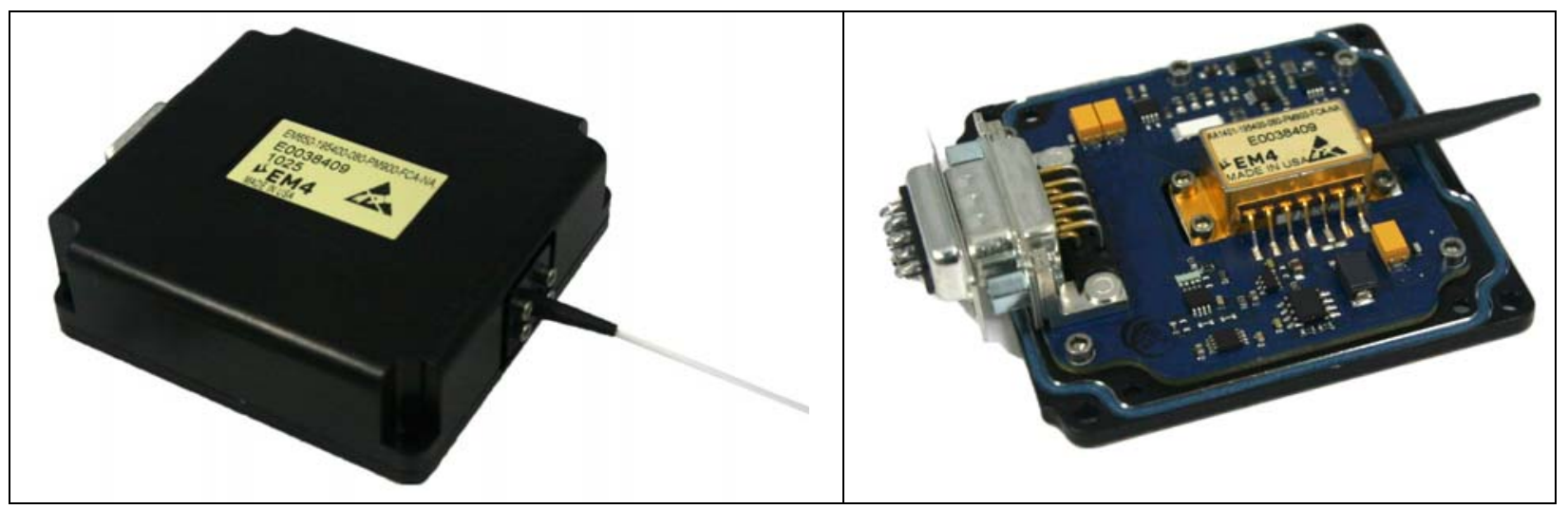

Figure 1. The EM650 laser transmitter module where size, weight and power (SWAP) have been greatly reduced by incorporating drive electronics into the same hermetic enclosure as the laser chip and coupling optics. The overall dimensions of this package is $\sim 2 "$ x 2 " x $0.5 "$.

The $1571 \mathrm{~nm}$ seed laser diodes are capable providing up to $100 \mathrm{~mW}$ whereas the $1262 \mathrm{~nm}$ laser diodes provide up to 3 $\mathrm{mW}$ of usable output power. The total volume of each module is less than $2 \mathrm{cu}$. in. The weight of each module is less than $0.25 \mathrm{lb}$ and the power Consumption is less than $1 \mathrm{~W}$.

\section{MEASUREMENT CHARACTERISTICS}

Both $1571 \mathrm{~nm}$ and $1262 \mathrm{~nm}$ modules were built and characterized in the laboratory. Figure 2 shows the wavelength tunability characteristics for the $1571 \mathrm{~nm}$ spectral band. . The wavelength tuning curves with the power adjust (PA) and temperature adjust features of the module. Greater than $2 \mathrm{~nm}$ tuning range has been demonstrated. Figure 3 shows similar curves for $1262 \mathrm{~nm}$ operation. The laser chips were obtained from nanoplus vendor. The measured wavelength characteristics is anticipated to satisfy our ASCENDS wavelength requirements.

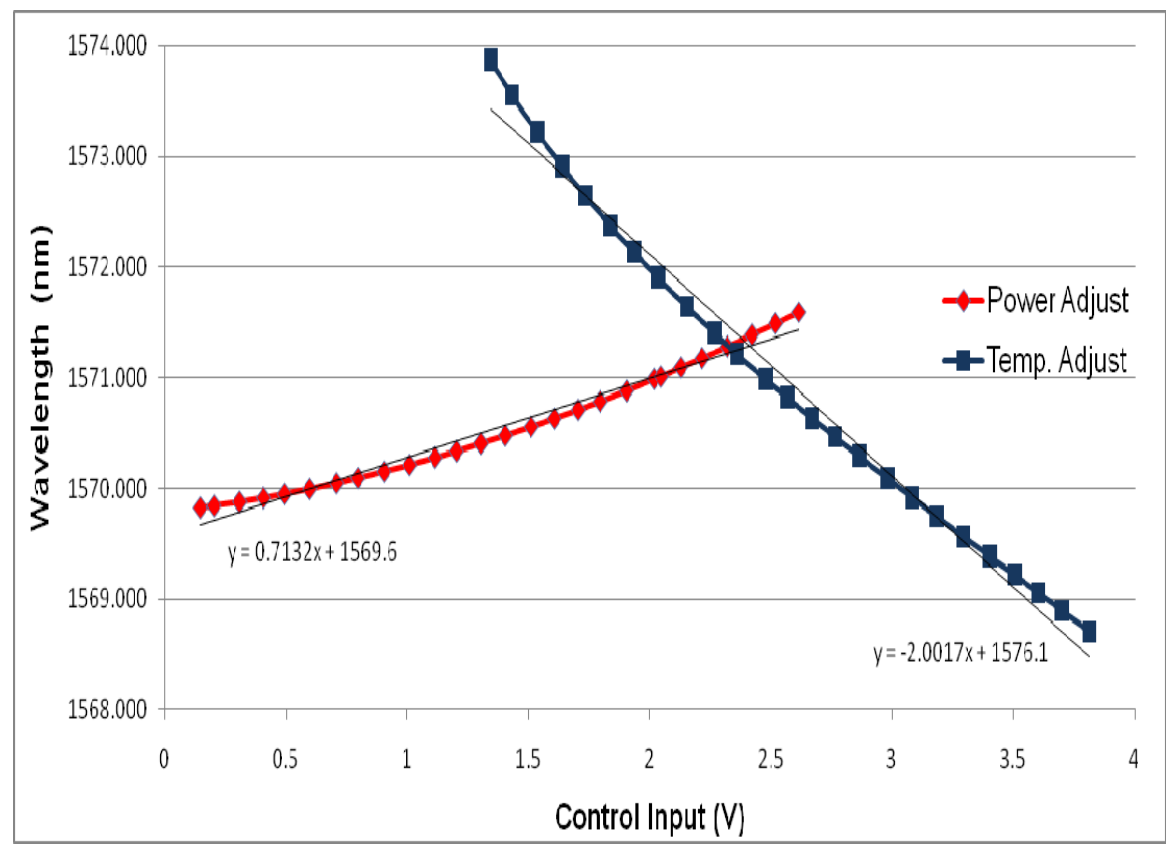

Figure 2. Wavelength tunability characteristics of EM650 for $1571 \mathrm{~nm}$ operation (a) Blue curve: Wavelength control by temperature, and (b) Red Curve: Wavelength control by Power adjust (current). 


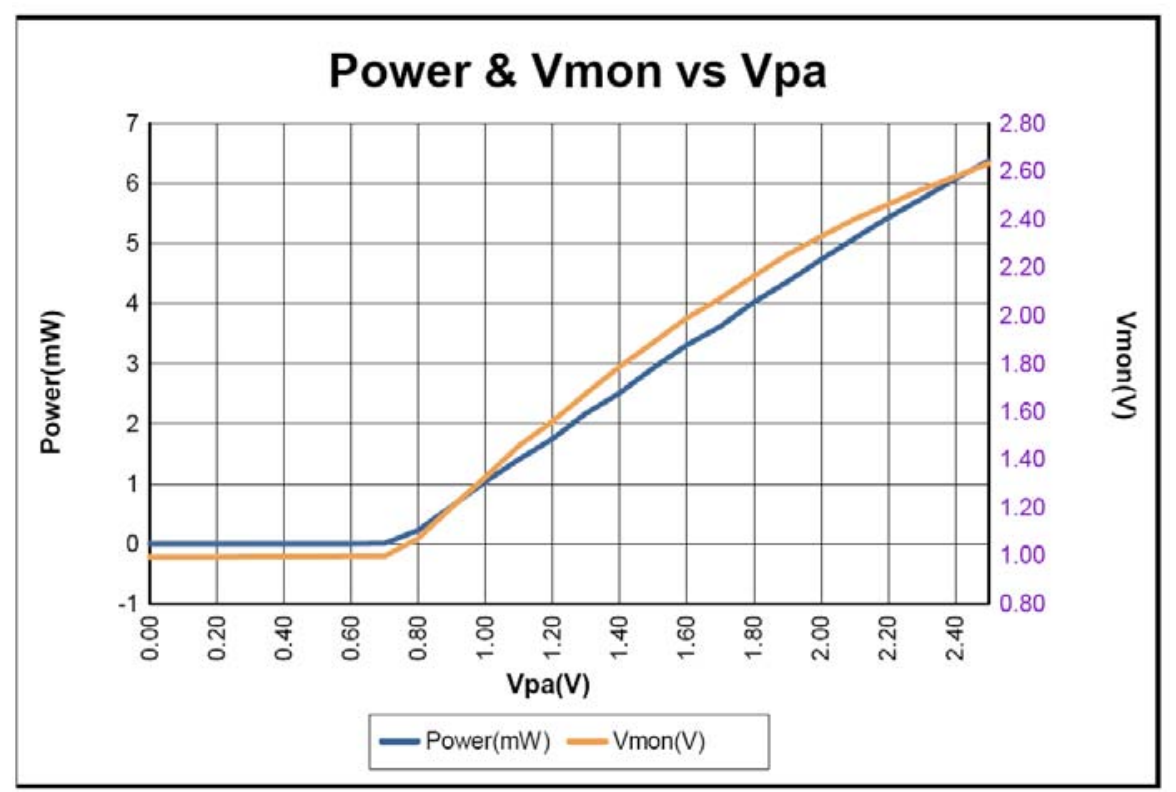

Figure 3. Output power characteristics of EM650 for $1262 \mathrm{~nm}$ operation (a) Blue curve: Output power vs. power adjust voltage (b) Red Curve: Monitor voltage vs. power adjust voltage.

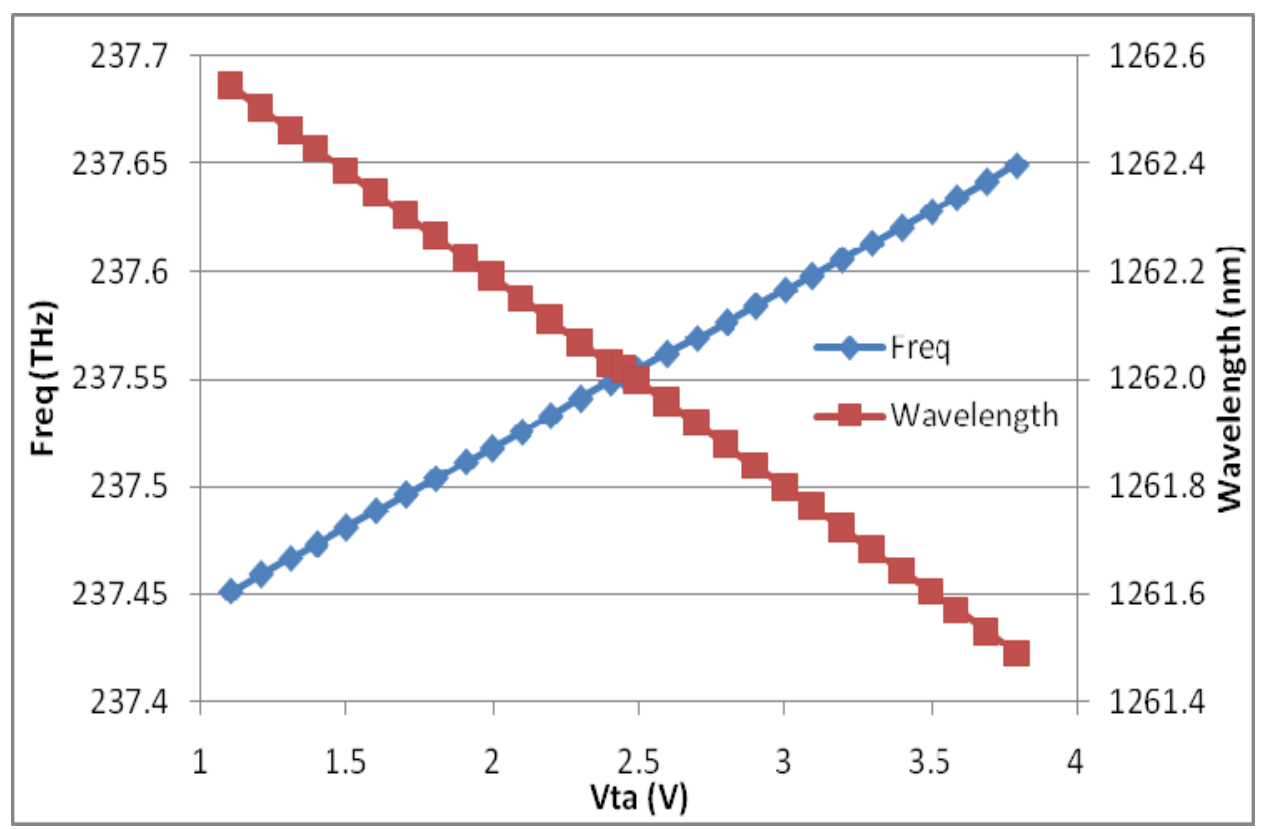

Figure 4. Wavelength and Frequency characteristics of $1262 \mathrm{~nm}$ module via temperature adjust control electronics 


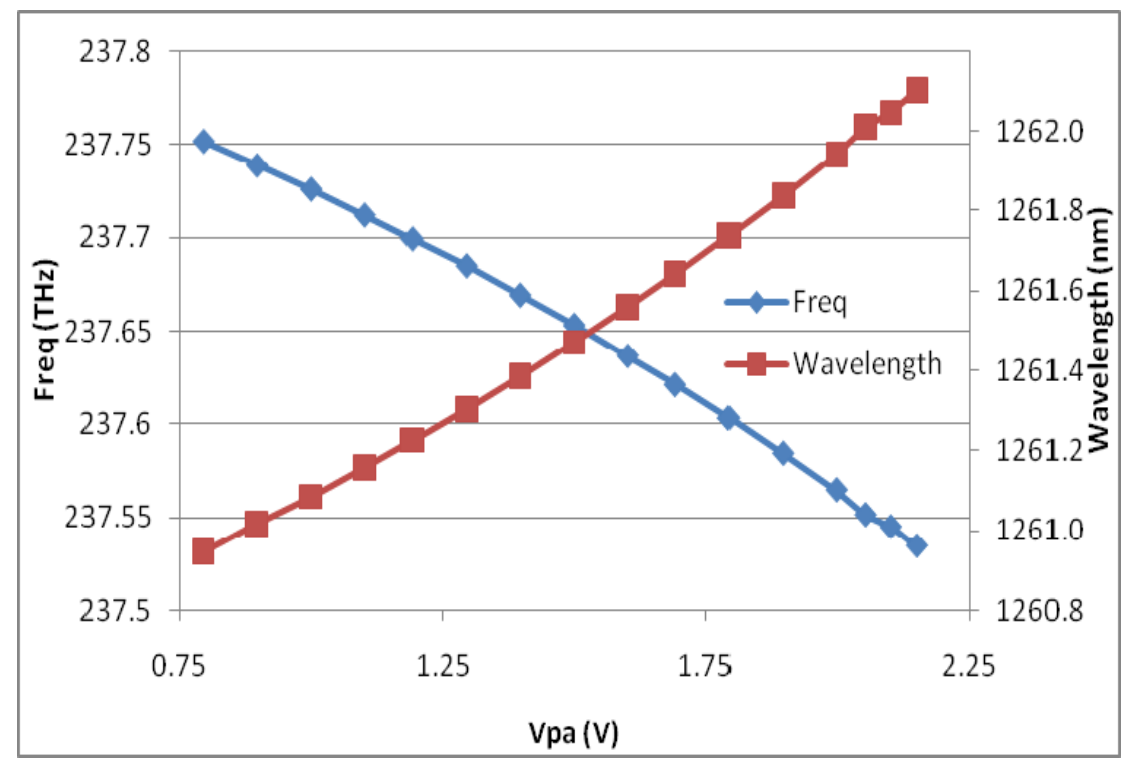

Figure 5. Wavelength and Frequency characteristics of $1262 \mathrm{~nm}$ module adjusted by power adjust.

\section{STABILITY MEASUREMENTS}

Following wavelength characterization, frequency and temperature stability were investigated. The heterodyne technique used to measure frequency stability is shown in Figure 6. Frequency stability was measured by heterodyning two free-running laser modules. Frequency offset was adjusted to $\sim 1 \mathrm{GHz}$. Commercial measurement systems, in general, are not capable of measuring line stability less than $200 \mathrm{MHz}(1.6 \mathrm{pm}$ at $\lambda=1550 \mathrm{~nm})$. The simple heterodyne technique provides a semi-quantitative measure of line positional stability and a qualitative comparison of linewidth.

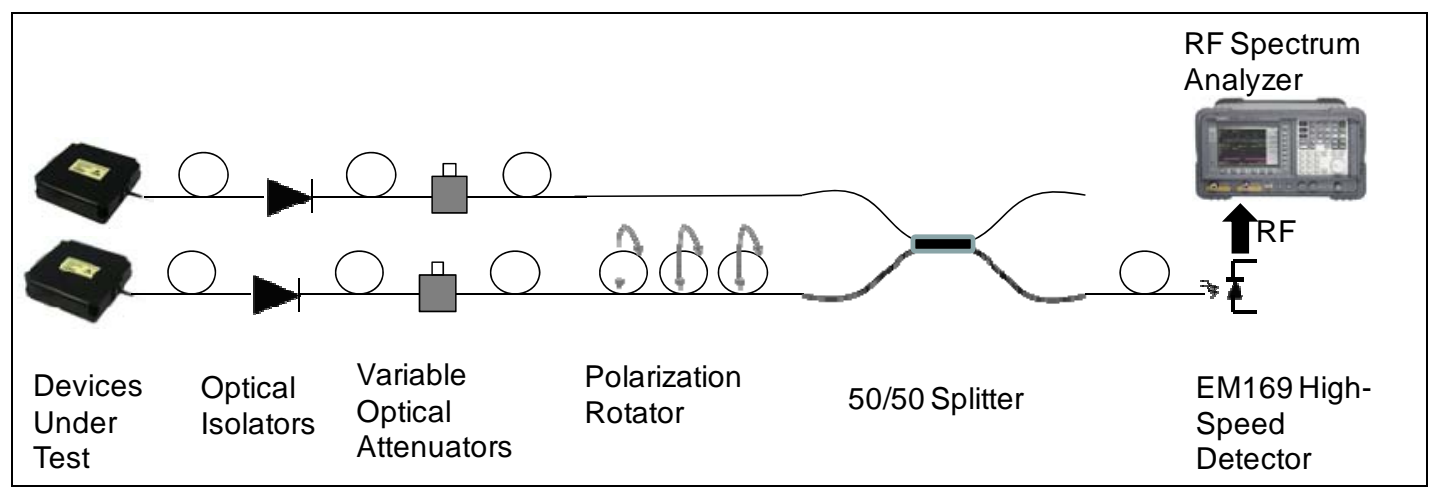

Figure 6. Wavelength and Frequency characteristics of $1262 \mathrm{~nm}$ module adjusted by power adjust.

Figure 7 shows the performance characteristics of EM650 operated using commercial drivers and inbuilt integrated drive electronics. The EM650 module with its integrated electronics shows a narrower difference frequency spectrum indicating a narrower laser linewidth is achieved. The peak of the waveforms shown can be monitored to determine the drift of the difference frequency over time. The assumption is that the drift is due to uncorrelated random sources in the two lasers generating the difference frequency. The EM650 varies by $4 \mathrm{MHz}$ pk-pk $(0.032 \mathrm{pm})$. The commercial 
controllers vary by $31 \mathrm{MHz}(0.248 \mathrm{pm})$. A video was recorded that showed the heterodyne signal of two free-running modules@ 1.6GHz with a span of 10MHz.

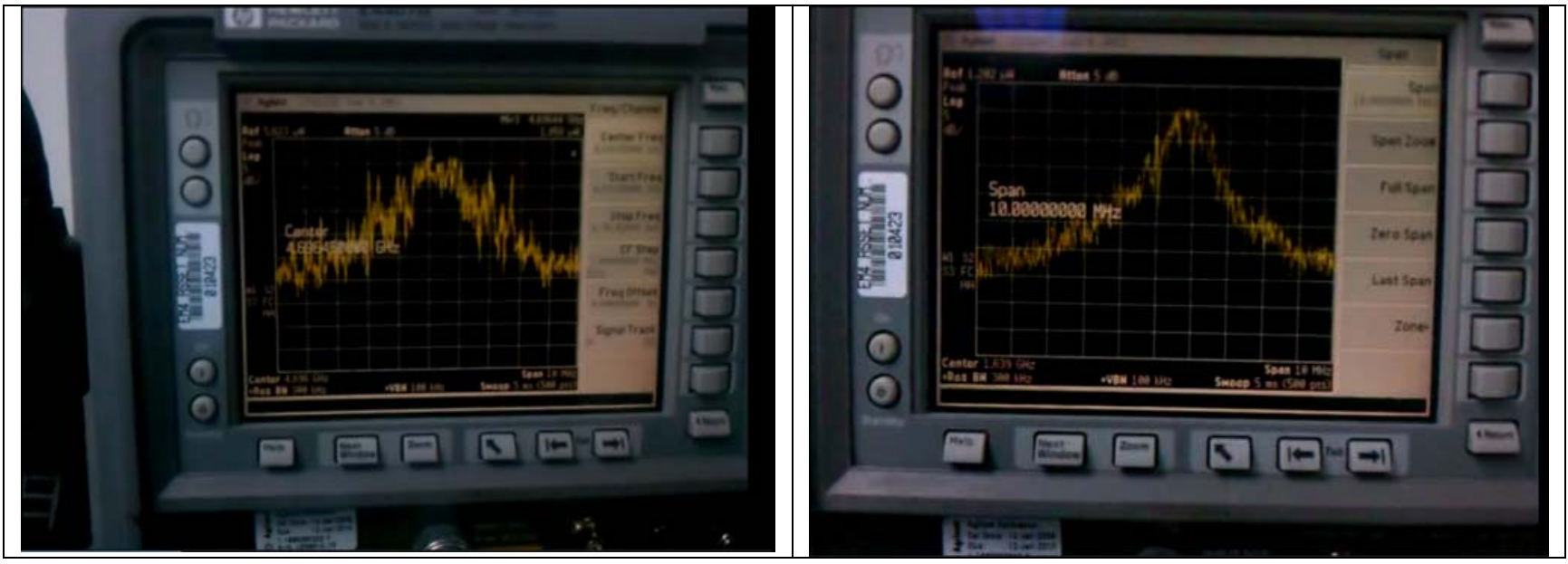

Figure 8. Linewidth characteristics of EM650. (a) EM4 DFBs operated using commercial available drivers. (b) COTS EM4 DFB modules operated using integrated driver electronics.

Next, temperature stability was investigated. Figure 9 shows Frequency excursion $<1 \mathrm{GHz}$ over $50^{\circ} \mathrm{C}$ range. Figure 10 illustrates the enhanced module design for low achieving SWaP. Smaller TEC and reduced heat-leaks improve the cooling efficiency of the laser module. Micro cooler has been incorporated to cooler the chip only and that resulted in improved temperature stability characteristics.

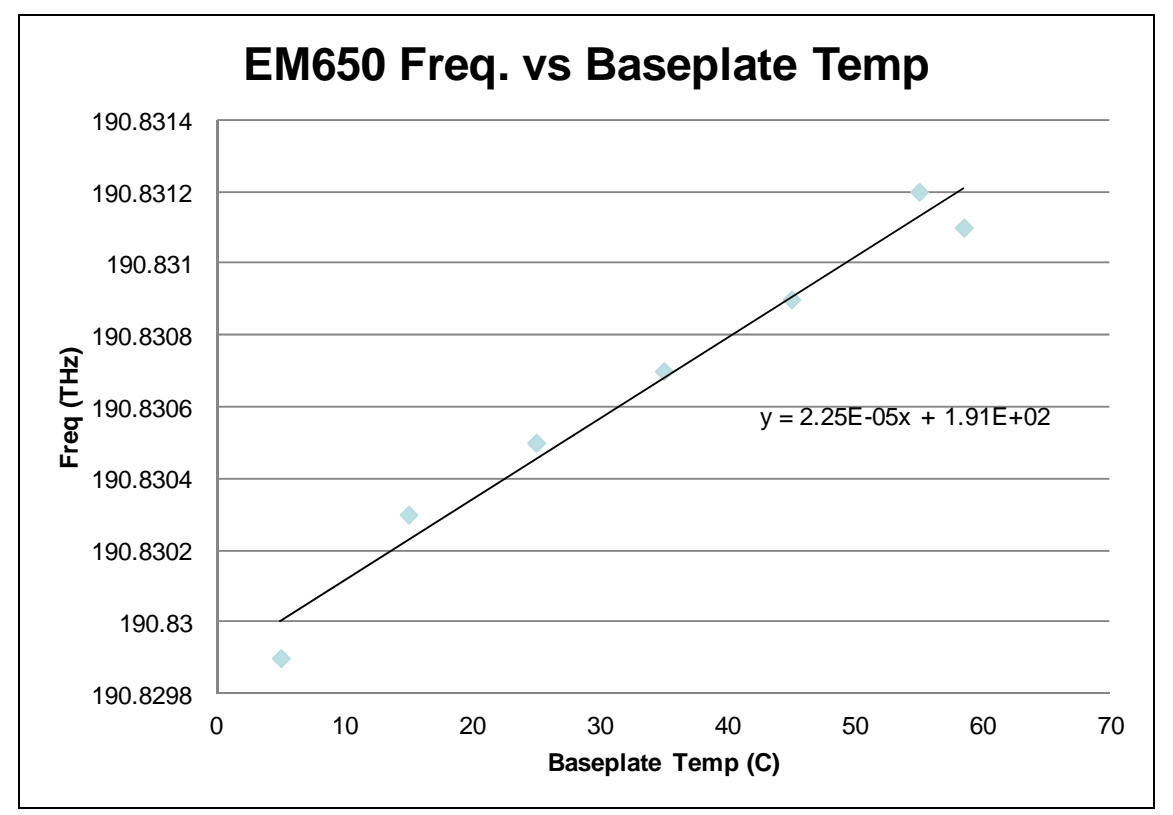

Figure 9. Temperature stability (frequency vs. baseplate temperature) measurements of EM650. 


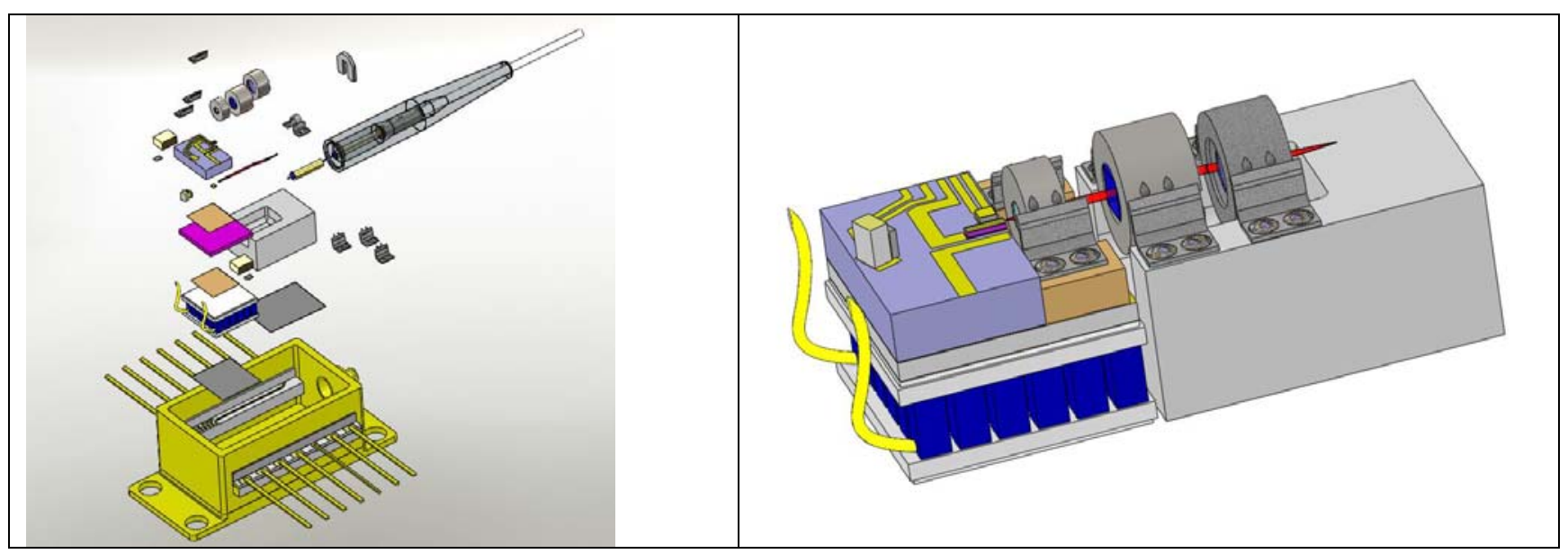

Figure 10. Design configuration of EM650 with microcooler incorporated below laser chip mount.

The coefficient of performance (COP) was measured with respect to ambient temperature. The COP is given by

$$
\text { CQR }=\frac{\text { Lasor Fowar - Outrut PQwar }}{\text { TEC VQlage XTEC Cwrent }}
$$

The COP improved $>10 \mathrm{X}$ compared to standard design (shown in blue and red curves) and this enables $>5 \mathrm{X}$ module efficiency. Our new integrated design configuration has resulted in improved Efficiency as shown in Figure 11. Figure 11 illustrates power consumption (W) vs. chip temperature minus ambient temperature $\left({ }^{\circ} \mathrm{C}\right)$. Up to $5 \mathrm{x}$ reduction in TEC control power consumption was achieved

\section{SPACE QUALIFIABLE ELECTRONICS DESIGN CONFIGURATION}

To facilitate operation from space based platforms at a later stage, the drive electronics was investigated for incorporating space qualifiable design elements to the extent possible and provide low SWaP. Accordingly, a low SWaP package with space qulifiable design elements was built and is ready for space qualification. The package shown in Figure 12 was built using proven high reliability organic-free, welded technology that has been space qualified. The new TEC was chosen using high reliability design with space qualification heritage. The electronics design with second iteration of electronics has been created using S-qual components is shown in Figure 13. The performance with S-Qual electronic design is similar to that of the commercial version. The space qualifiable design version was approximately 2x larger than the COTS design footprint due to size of S-qual components. Further work to reduce SWaP with S-Qual components and test under relevant environment is being planned. 


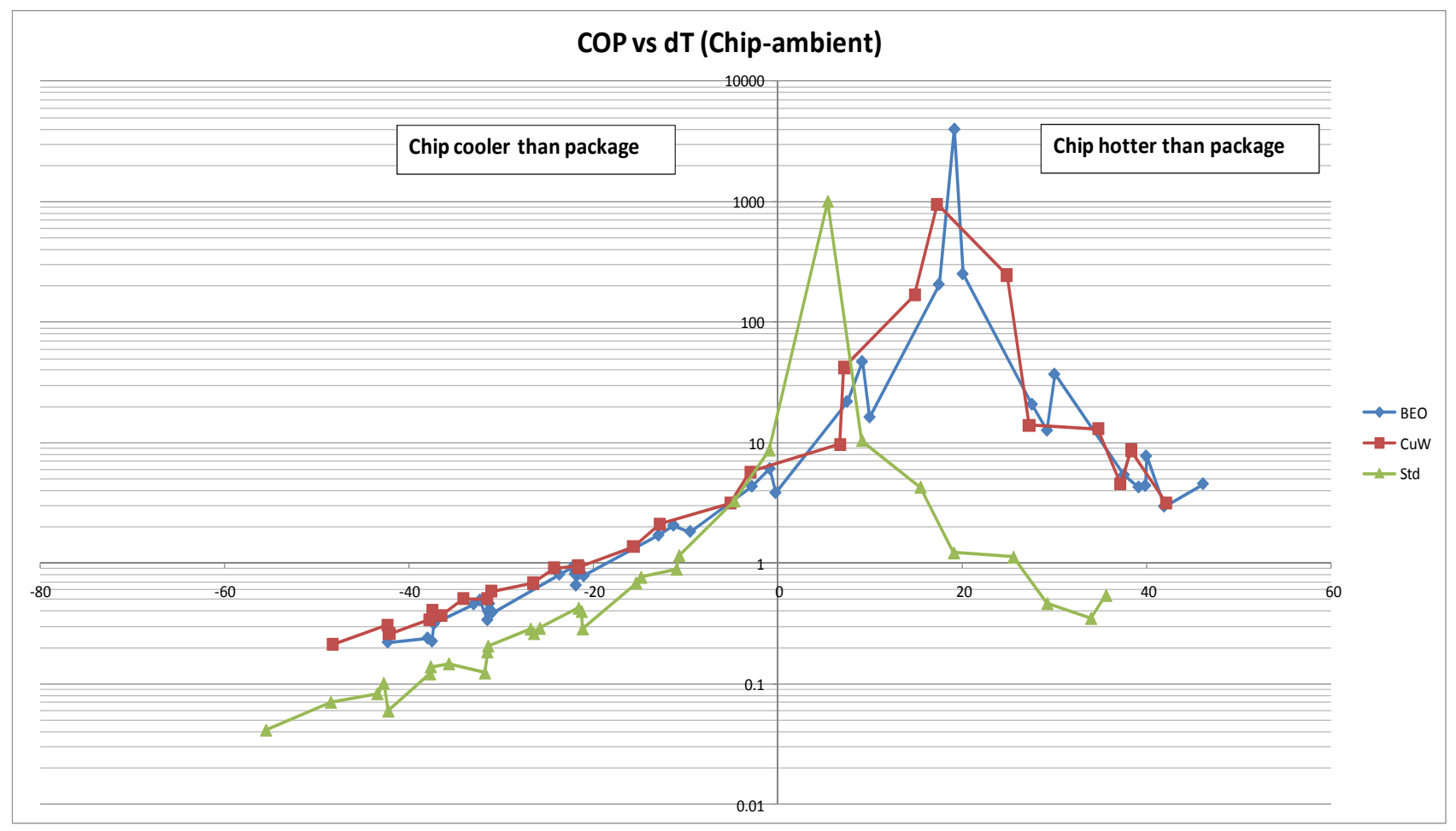

Figure 11. COP vs. chip minus ambient temperature.

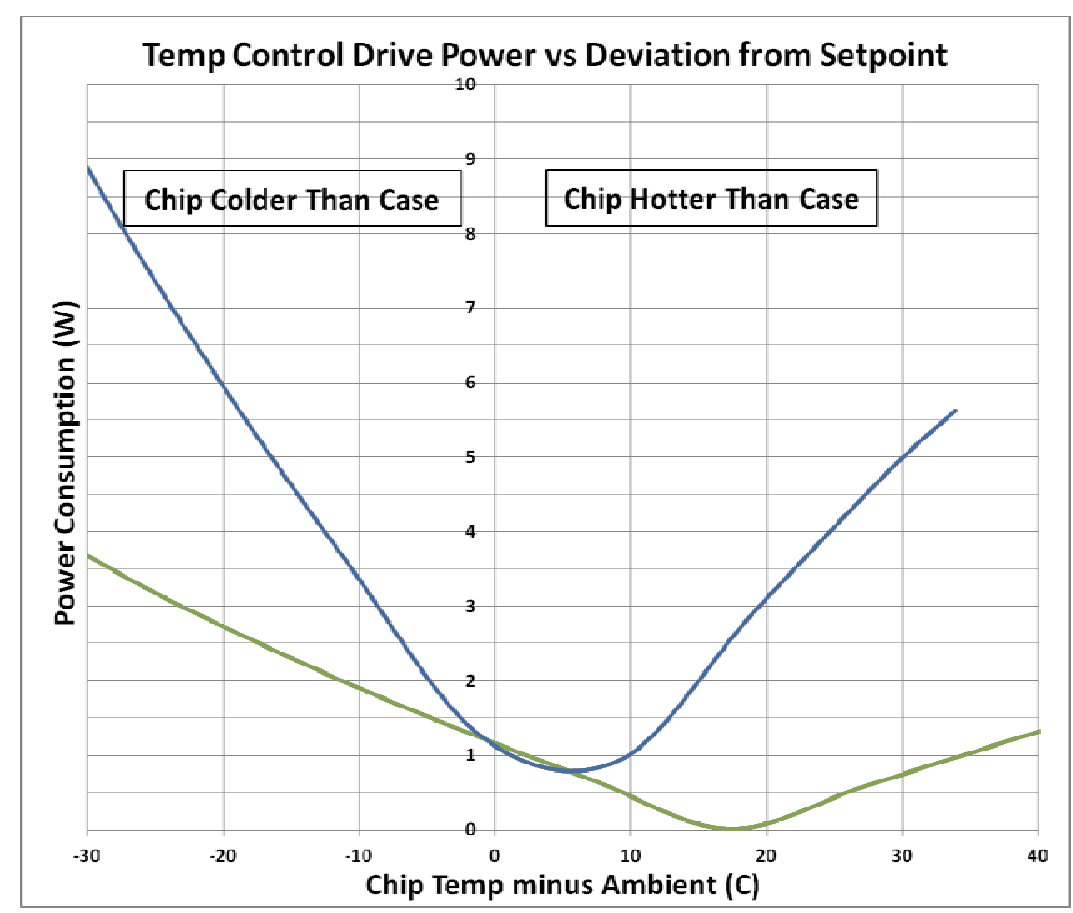

Figure 12. Power consumption enehnacement with the new integrated design configuration of EM650. 


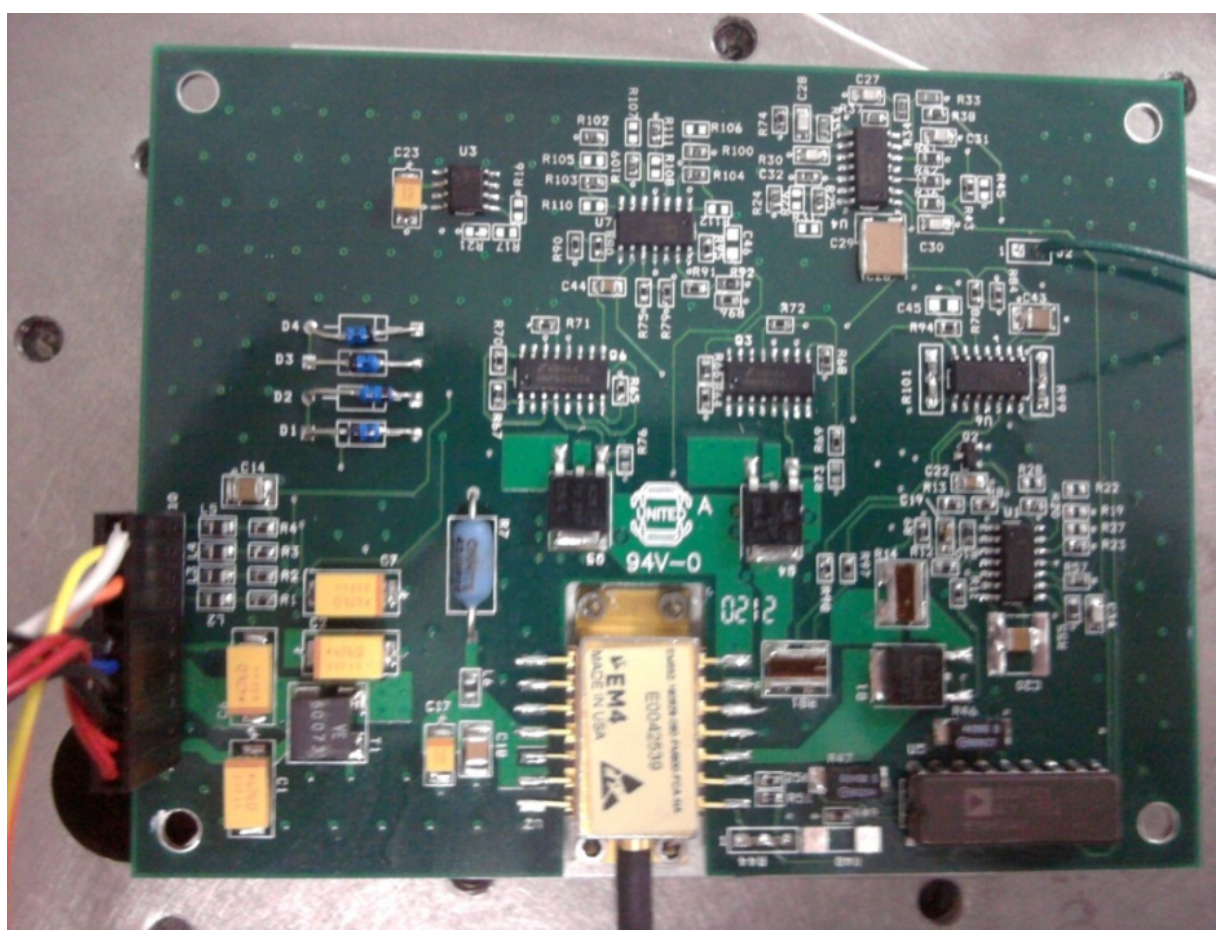

Figure 13. Space qualifiable design of electronics circuit board.

\section{SUMMARY AND CONCLUSIONS}

Compact transmitter designs for ASCENDS mission applications are being explored. Seed laser modules with integrated drive electronics for operation in $1571 \mathrm{~nm}$ and $1262 \mathrm{~nm}$ spectral band for $\mathrm{CO} 2$ and $\mathrm{O} 2$ sensing respectively are being designed and tested. Current status of our enhanced seed laser modules include:

- Total volume less than $2 \mathrm{cu}$. In.

- Max O/P power is $100 \mathrm{~mW} @ 1571 \mathrm{~nm}$

- Max O/P power is $3 \mathrm{~mW} @ 1262 \mathrm{~nm}$

- Weight $<\sim 0.25 \mathrm{lb}$

- Power Consumption $<1 \mathrm{~W}$

The overall goal is to build a transmitter with three seed laser modules for $\mathrm{CO} 2$ sensing with associated front-end electronics with $<10 \mathrm{cu}$. in. One or more seed laser modules will be coupled to single or multiple erbium doped fiber amplifiers (EDFA) modules for achieving $5 \mathrm{~W}$ or more output power.

\section{REFERENCES}

1. NRC, Earth Science and Applications from Space: National Imperatives for the Next Decade and Beyond, The National Academies Press, Washington, D.C., 2007.

2. ASCENDS, NASA Science Definition and Planning Workshop Report, NASA ASCENDS Workshop, 
University of Michigan,

3. Alex Rosiewicz, Steve Coleman, Narasimha Prasad, "Development of Low SWAP Laser Transmitters at $1262 \mathrm{~nm}$ and 1571nm," Proc. Of SPIE vol. 7912, pp791206-1, (2011)

4. Narasimha S. Prasad, Alex Rosiewicz, Steven M. Coleman, "Development of a Low SWaP Laser Transmitter for Atmospheric Lidar Applications,” 2009 AGU Fall Meeting, San Francisco, CA, 14-18 December, 2009.

5. http://www.em4inc.com/product_Integrated_Module.htm 